\title{
PulseNet Latin America and the Caribbean Network: Present and Future
}

\author{
Isabel Chinen,, Josefina Campos, ${ }^{1}$ Tshewang Dorji, ${ }^{2}$ and Enrique Pérez Gutiérrez ${ }^{2}$
}

\begin{abstract}
PulseNet Latin America and Caribbean (PNLAC) was established in 2003 and is one of seven Regional networks within PulseNet International. The main objectives of the network are to strengthen national and regional laboratorybased foodborne disease surveillance for early detection and investigation of outbreaks to setup control and prevention strategies in contribution to Public Health. Participants perform standardized pulsed-field gel electrophoresis (PFGE) protocols and analysis. For functioning, it is important for the network, the development of national and regional databases (RDBs) and the communication between countries, regionally and internationally. Metadata from over 8600 cases/outbreaks are profiled and isolated by PFGE and are incorporated into the RDB, hosted by the Pan American Health Organization. Currently PNLAC is moving toward whole-genome sequencing to use as a complementary strategy for surveillance. The aim of this article was to describe the experience of the construction of PNLAC, and its contribution to the surveillance of the foodborne diseases at the country and regional levels.
\end{abstract}

Keywords: surveillance, Public Health, Foodborne Pathogens and Disease Surveillance

\section{Introduction}

$\mathbf{P}$ UlseNet Latin America and Caribbean (PNLAC) was established in 2003 and is one of seven regional networks within PulseNet International (PNInt). The main objective is to strengthen national and regional laboratory-based foodborne disease surveillance for early detection and investigation of outbreaks, to setup control, and prevention strategies in contribution to Public Health. Participants perform standardized pulsed-field gel electrophoresis (PFGE) protocols and analysis. Each country creates the national database (NDB) with PFGE patterns obtained using standardized protocols to monitor the strains circulating in the country according to how each country established their surveillance system, and works in connection with other participants through the regional database (RDB), in contribution to the regional surveillance. Metadata from over 8600 cases/outbreaks are profiled and isolated by PFGE and are incorporated into the RDB, hosted by the Pan American Health Organization (PAHO). Currently, PNLAC is moving toward whole-genome sequencing (WGS) to use as a complementary strategy for surveillance.

Participants of PNLAC are considered low-income countries, regarding their social and economic contexts. Nevertheless, we have recognized the need of the integration as region into the global surveillance. Therefore, the building of the network was accomplished with the effort of each PNLAC member, with a process of training in subtyping techniques, and also learning how to work as a team. The continued growth was essential to maintain the results comparable to international standards. It is important to mention that the functioning was partially supported by different international partnerships. The aim of this article is to describe the experience of the construction of PNLAC network, and its contribution to foodborne disease surveillance at the country and regional levels.

\section{New Network Structure}

PNLAC has grown since its creation in 2003 when it started with 13 founding members. Between 2006 and 2013, PNLAC included three additional countries (Ecuador, Guatemala, Panamá) and the 22 countries of the Caribbean Region through the integration of Caribbean Public Health Agency (CARPHA) Subregional reference laboratory (RRL), into the network. Since 2014, food and animal agency laboratories in Mexico, Colombia, and Argentina joined PNLAC as part of the National Surveillance. Today, PNLAC

\footnotetext{
${ }^{1}$ National Administration of Laboratories and Health Institutes - ANLIS "Dr. Carlos G. Malbrán," Buenos Aires, Argentina.

${ }^{2}$ Health Emergency Information and Risk Assessment, Health Emergencies Department, Pan American Health Organization/World Health Organization (PAHO/WHO), Washington, District of Columbia.

(C) Isabel Chinen et al. 2019; Published by Mary Ann Liebert, Inc. This Open Access article is distributed under the terms of the Creative Commons License (http://creativecommons.org/licenses/by/4.0), which permits unrestricted use, distribution, and reproduction in any medium, provided the original work is properly cited.
} 


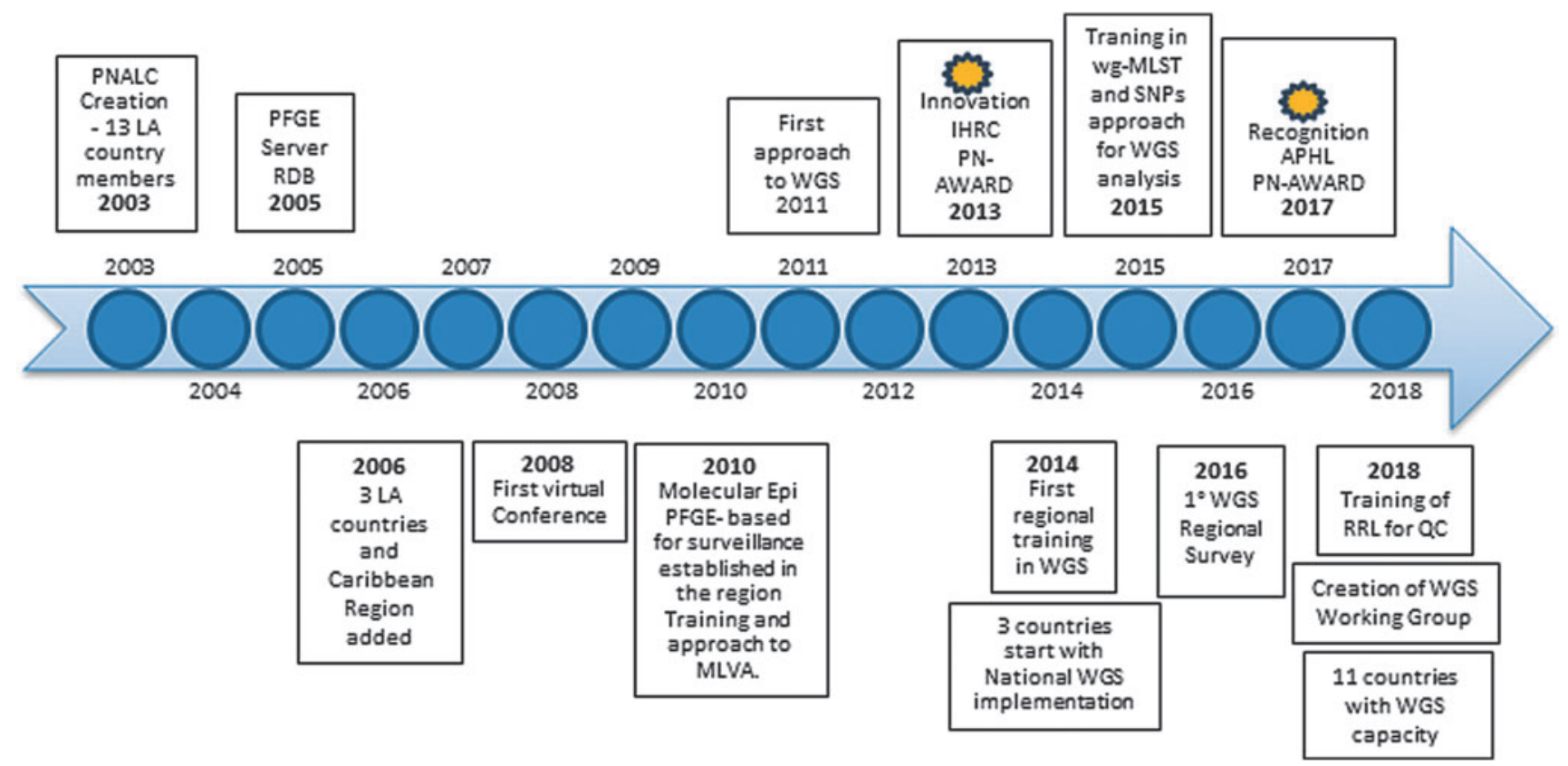

FIG. 1. Timeline marking the progress of PNLAC. Main events important to the enhancement of the network. APHL, American Public Health Laboratories; IHRC, International Consulting; LA, Latin America; MLVA, Multiple-Locus Variable-Number Tandem Repeat Analysis; PFGE, pulsed-field gel electrophoresis; PN, PulseNet; QC, quality control; RDB, regional database; RRL, Regional Reference Laboratory; wg-MLST, whole genome-Multilocus Sequence Typing; WGS, whole genome sequencing.

network is made up of 24 reference laboratories/agencies from 16 countries of Latin America (LA) and the Caribbean Region: Argentina, Bolivia, Brazil, Chile, Colombia, Costa Rica, Cuba, Ecuador, Guatemala, Nicaragua, México, Panamá, Paraguay, Perú, Uruguay, Venezuela, and CARPHA. Each member country is part of the assembly that represents the highest authority in the network within the boundaries of its expertise. The members are in charge of the implementation of the subtyping techniques, and fulfill the requirement to work and exchange information in the network. Technical Coordination Unit comprises PAHO/World Health Organization (WHO) and the Instituto Nacional de Enfermedades Infecciosas (INEI)-ANLIS “Dr. Carlos G. Malbrán" (RRL), who coordinates both activities and communication among members (Fig. 1).

\section{Innovation for Communication and Training}

PNLAC works to strengthen communication between countries within the network. An innovative tool, a web conferencing platform, has been used since August 2008, to facilitate meetings and trainings. Up to date, the platform has hosted 28 conferences with an average of 12 countries participating each time. Some topics discussed include: outbreak investigations in each country, international alerts and news related to the International Health Regulations (IHR), troubleshooting on PFGE issues, quality assurance (QA) program (certifications/proficiency tests), and projects and reports from PNInt. The conferences are recorded and a summary is sent to all members. Training activities were also performed over the virtual platform, including: a complete advance course in PFGE BioNumerics (BN) analysis (2010: four sessions); a step-by-step video about PFGE laboratory pro- cedures (2010: distributed to PNLAC and PNInt participants and uploaded to internet for general public access. http:// www.youtube.com/user/pulsenetint?feature=watch); a workshop to enhance the knowledge on WGS with different international speakers (2017: seven sessions); and the organization of the annual meetings and workshops with the contribution of different countries. In recognition of PNLAC's of the advances done in the network and in new technologies for better communication and training for their members, PNLAC was awarded with the IHRC Innovations in PulseNet Award carried out in the 2013 Integrated Foodborne Outbreak Response and Management (InFORM) Conference on "PulseNet, OutbreakNet, and Environmental Health." Additionally, INCIENSA, Costa Rica, an active member of PNLAC, was awarded for their achievements in introducing WGS during InFORM Association of Public Health Laboratories Conference in 2017.

Continuous training through courses and workshops were essential to keep the network updated. Over 14 seminar sessions, workshops, and training courses were performed during PNLAC Annual Meetings. Systematic training supported staff in improving management and interpretation of results to improve national and regional surveillance systems. Additional workshops were organized in collaboration with WHO to complement training with epidemiological topics related to foodborne illness source attribution, burden of diseases, and integrated surveillance for foodborne pathogens. Moreover, partnerships with different institutions worldwide were the primer to promote the initiative in the network for working in new technologies. As an example, in 2010, Center for Disease Control and Prevention (CDC) experts trained PNLAC members from Chile, Brazil, and Argentina in Multiple-Locus Variable-Number Tandem 
Repeat Analysis as a new strategy for molecular surveillance. In 2011, PNLAC worked to introduce WGS, and has continued providing trainings on WGS laboratory protocol and different strategies for sequence analysis.

Since 2005, a total of 16 PFGE training missions were important to strengthen the capacity in 13 countries and the Caribbean Region. Moreover, the RRL and other laboratories of the network have received visits from PNLAC members to reinforce the knowledge and abilities for PFGE implementation in their countries.

PNLAC network promotes the possibility of consulting with other members of the network or of other regional PulseNet networks or PNInt to work in cooperation to solve epidemiological issues. The exchange of experiences with other regions of PNInt is always an opportunity of learning. As example, PNLAC participated in the Asia Pacific (2010) and the Middle East (2010/2012) PulseNet Regional Meetings. As well as, in 2015, PNLAC had the opportunity to host members from other PulseNet regions in the framework of the Annual Meeting with PNInt.

\section{Strength of the Network}

\section{QA/quality control}

Up to date, the countries accomplish the QA/quality control (QC) program that supports the quality of the PFGE data, through the certification process of the organism(s) of interest for national surveillance; the certification is maintained by the Annual Proficiency Testing performed by both the RRL and CDC.

\section{Surveillance and outbreak investigation by PFGE}

The technical and operational capacity of the network has improved gradually in each country according to the different social, economic, and cultural realities. At the beginning, PFGE implementation was incorporated in the surveillance strategies for Salmonella spp. and Escherichia coli. The protocol for the surveillance of Shigella sonnei, Shigella flexneri, Listeria monocytogenes, Vibrio cholerae, and Vibrio parahaemolyticus were adopted as requirement of the country.

In 2006, the RDB was created. It was a great effort for the region and different considerations were taken into account to have the installed capacity available for the participants. The server has been placed in PAHO, as a neutral location, and also to ensure the safe access from each country to the server, as well as the internet connectivity, security, and privacy. The maintenance and support of the RDB are performed by an IT staff member, trained at CDC for informatics and bioinformatics maintenance regional curators.

The RDB has increased in number with data from surveillance and different projects. Currently, PNLAC has the RDB for Salmonella, Shigella, E. coli, L. monocytogenes, V. cholerae, and Campylobacter. Among the 7602 isolates in the LAC PulseNet Database from 2004 to 2017, majority $(85.7 \%)$ were isolated from humans, followed by food $(6.3 \%)$ and animal (4.9\%). Environmental and QA samples represented the lowest proportions of the isolates in the database (Fig. 2).

The data at RDB are complemented by those in each NDB, and through a consultation by email we could rapidly get the
Proportion of isolates in the Pulsenet Latin America and Caribbean (PNLAC) network between 2004 and 2018 by isolate source type

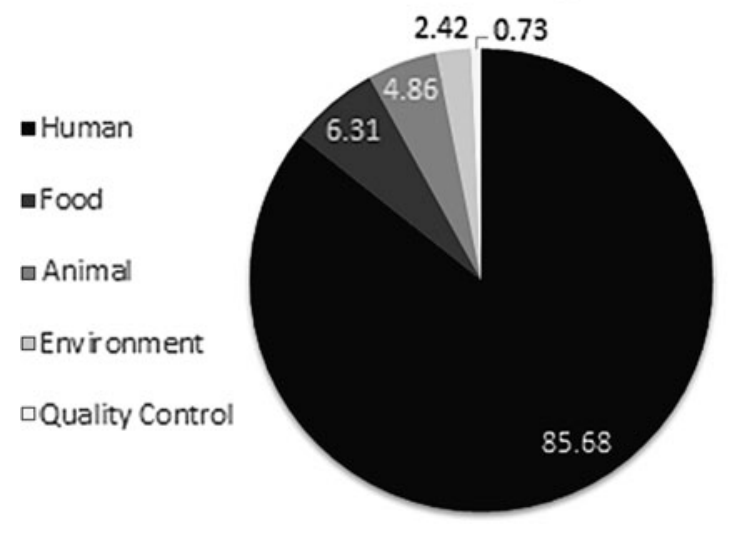

FIG. 2. Proportional distribution of the isolates in the Regional Database of PulseNet Latin America and the Caribbean Network Regional Database by source of origin, from 2004 to 2017.

national information. With the RDB and NDB, the QC program, and the participants trained, each country could address outbreaks or clusters to give response to public health issues (Table 1).

During these years, the time from receiving the sample and uploading PFGE pattern to RDB has improved. We calculated time (number of days) from the date the isolate was received at the national laboratory to the date the PFGE pattern was uploaded to the RDB with the corresponding metadata between 2004 and 2018. The overall median time from the date the isolate was received at the laboratory to the date the isolate PFGE pattern was uploaded to the RDB was $187 \mathrm{~d}$ (range 1-1111 d), with marked reductions in timeapproximately $48 \mathrm{~d}$-between each progressive year the isolates were received since the network was set up.

The relationship and distribution of genetic subtypes of the pathogens monitored by the network, from the analysis of PNLAC RDB are presented below.

Approximately $54.4 \%$ of the isolates received between 2004 and 2018 have been Salmonella spp., the most frequently reported pathogen to the RDB (Fig. 3).

Salmonella enterica serovar Typhi. Salmonella enterica serovar Typhi isolates were diverse, showing 329 XbaIPFGE patterns among 967 isolates from 11 countries: Argentina, Bolivia, Brazil, Chile, Colombia, Costa Rica, Guatemala, Paraguay, Peru, Uruguay, and Venezuela. Of those, 43 patterns were found in more than one country. Of these shared patterns, ALJPPX01.0147 and ALJPPX01.0027 were associated with outbreak. Table 2, summarizes the information of ten most frequently identified XbaI-PFGE Salmonella Typhi patterns found in more than one country. The frequency of each pattern in the RDB, the country, and year of pattern upload are also shown. In 2012, an initial analysis was done with 48 Salmonella enterica serovar Typhi XbaI-PFGE patterns among 70 isolates from four countries between 2005 and 2009 (Campos et al., 2012). None of those PFGE profiles was found in more than one country. In 2016, it was reported 
Table 1. Outbreaks Studied by Pulsed-Field Gel Electrophoresis in the Last 2 Years in Countries of PulseNet Latin America and Caribbean

\begin{tabular}{|c|c|c|c|}
\hline & $\begin{array}{l}\text { No. of outbreaks } \\
\text { analyzed by PFGE }\end{array}$ & Countries & Pathogen associated \\
\hline Salmonella & 88 & $\begin{array}{l}\text { Brazil, Guatemala, } \\
\text { Paraguay, Perú, } \\
\text { Uruguay, Colombia, } \\
\text { Argentina }\end{array}$ & $\begin{array}{l}\text { Serovar: Anatum, Derby, I, 4,5,12:i:-, } \\
\text { Oranienburg, Infantis, Typhi, Enteritidis, } \\
\text { Newport, Agona, Cerro, Montevideo, } \\
\text { Javiana, Schwarzengrund, Worthintong, } \\
\text { Bellevue, Uganda, Weltevreden, Hadar, } \\
\text { Dublin, Braenderup, Lagos, Paratyphi, } \\
\text { Gallinarum, Chester, London }\end{array}$ \\
\hline Shigella & 10 & $\begin{array}{l}\text { Colombia, Costa Rica, } \\
\text { Argentina }\end{array}$ & Shigella sonnei (5), Shigella flexneri (5) \\
\hline STEC & 40 & Argentina & $\begin{array}{l}\text { Escherichia coli O157, Escherichia coli } \\
\text { O121, Escherichia coli O145 }\end{array}$ \\
\hline Vibrio & 1 & Colombia & Vibrio cholerae \\
\hline Serratia & 2 & Costa Rica & Serratia liquefaciens, Serratia marcescens \\
\hline $\begin{array}{l}\text { Cronobacter } \\
\text { sakazakii }\end{array}$ & 2 & Costa Rica, Argentina & C. sakazakii \\
\hline E. coli & 1 & Cuba & $D E C$ \\
\hline
\end{tabular}

PFGE, pulsed-field gel electrophoresis; STEC, Shiga toxin-producing Escherichia coli.

that $81 \%$ were isolated from sporadic cases and $19 \%$ from cases associated to outbreak. Only $6.79 \%$ of the strains showed antimicrobial resistance and $0.36 \%$ were multiresistant (Díaz et al., 2016).

Salmonella enterica serovar Typhimurium. A total of 424 XbaI-PFGE patterns were identified in the RDB among 1322 Salmonella enterica serovar Typhimurium isolates from nine countries: Argentina, Barbados, Bolivia, Brazil, Chile, Colombia, Costa Rica, Guatemala, and Paraguay. Table 3, summarizes the information of the ten most frequent Salmonella enterica serovar Typhimurium XbaI-PFGE patterns found in more than one country. In 2012, it was reported that $226 \mathrm{XbaI}$-PFGE patterns were identified in the RDB among 554 Salmonella enterica serovar Typhimurium isolates from six countries: Argentina, Brazil, Chile, Colombia, Costa Rica, Paraguay (2005-2009) (Campos et al., 2012).

Salmonella enterica serovar Enteritidis. A total of 41 $X b a I-P F G E$ patterns were identified among 541 isolates from

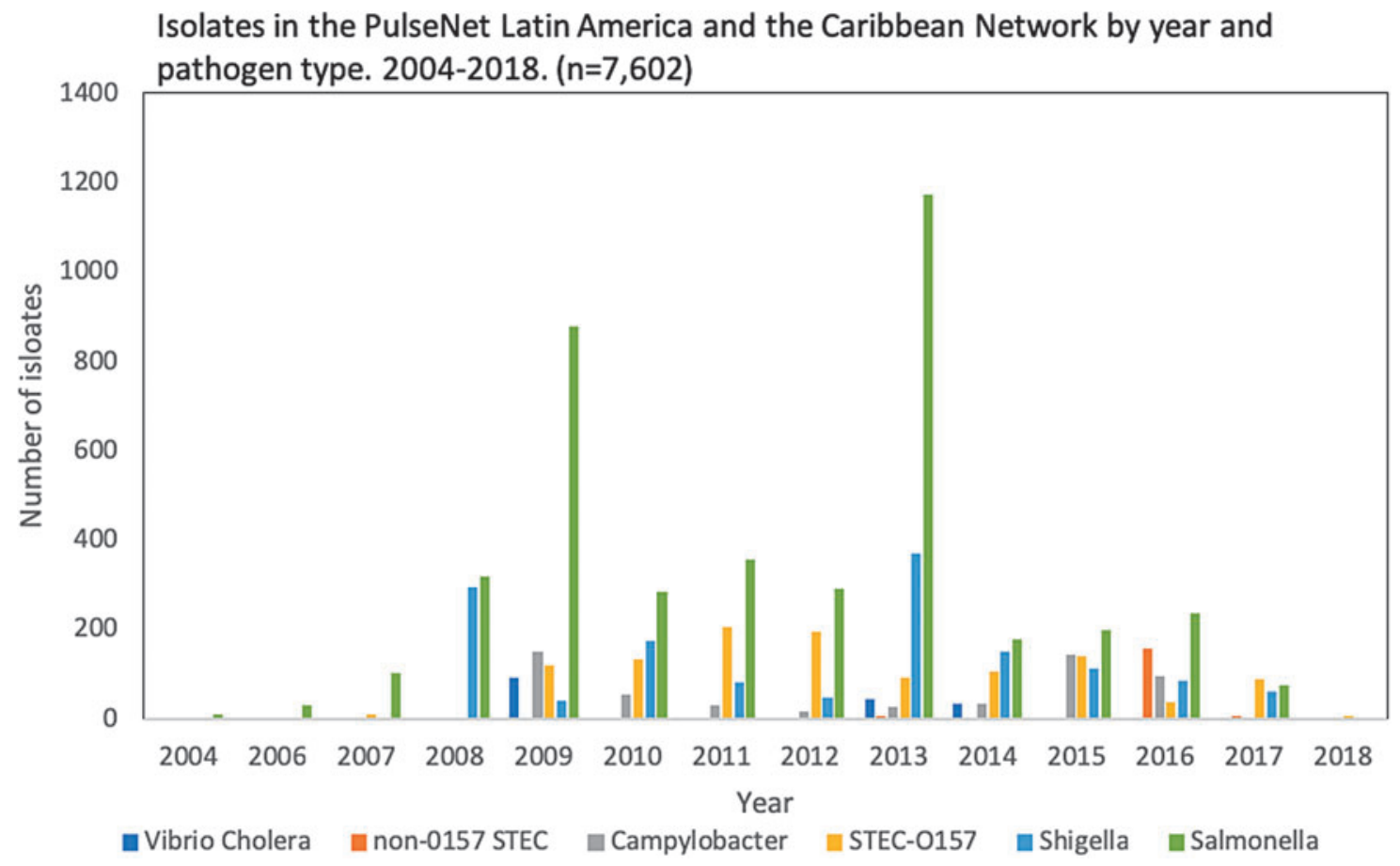

FIG. 3. Isolates in the Regional Database of PulseNet Latin America and the Caribbean Network by year and pathogen type, from 2004 to 2018 ( $n=7602)$. STEC, Shiga toxin-producing Escherichia coli. 
Table 2. Salmonella enterica Serovar Typhi XbaI Pulsed-Field Gel Electrophoresis Patterns Present in More Than One Country and Frequency of Distribution in the Regional Database from 2004 to 2017

\begin{tabular}{|c|c|c|c|}
\hline $\begin{array}{l}\text { PFGE } \\
\text { pattern no. }\end{array}$ & $\begin{array}{c}\text { Frequency in data among } \\
\text { Salmonella Typhi isolates } \\
(\%)\end{array}$ & Countries & Years \\
\hline \multirow[t]{4}{*}{ ALJPPX01.0016 } & $5.17 \%$ & Argentina & 2004 and 2009 \\
\hline & & Chile & 2009, 2011 and 2013 \\
\hline & & Colombia & 2009, 2011 and 2013-2014 \\
\hline & & Peru & 2014 \\
\hline \multirow[t]{3}{*}{ ALJPPX01.0048 } & $3.93 \%$ & Argentina & 2009 \\
\hline & & Chile & 2009 and 2013 \\
\hline & & Colombia & 2011 and 2013 \\
\hline \multirow[t]{2}{*}{ ALJPPX01.0167 } & $3.93 \%$ & Brazil & 2013 \\
\hline & & Chile & 2013 \\
\hline \multirow{3}{*}{ ALJPPX01.0026 } & $2.38 \%$ & Argentina & 2009 \\
\hline & & Brazil & 2009 \\
\hline & & Guatemala & 2013-2014 \\
\hline \multirow[t]{2}{*}{ ALJPPX01.0076 } & $1.65 \%$ & Colombia & 2009 and 2013 \\
\hline & & Venezuela & 2014 \\
\hline \multirow[t]{5}{*}{ ALJPPX01.0080 } & $1.45 \%$ & Brazil & 2010 \\
\hline & & Chile & 2013 \\
\hline & & Colombia & 2009, 2011 and 2013 \\
\hline & & Peru & 2014 \\
\hline & & Venezuela & 2014 \\
\hline \multirow{2}{*}{ ALJPPX01.0123 } & $1.34 \%$ & Chile & 2013 \\
\hline & & Colombia & 2009, 2011 and 2013-2014 \\
\hline \multirow[t]{3}{*}{ ALJPPX01.0147 } & $1.24 \%$ & Chile & 2011 \\
\hline & & Colombia & 2013 \\
\hline & & Venezuela & 2014 \\
\hline \multirow[t]{4}{*}{ ALJPPX01.0019 } & $1.03 \%$ & Argentina & 2009 \\
\hline & & Chile & 2011 and 2013 \\
\hline & & Colombia & 2013 \\
\hline & & Peru & 2014 \\
\hline \multirow[t]{6}{*}{ ALJPPX01.0027 } & $1.03 \%$ & Argentina & 2004 \\
\hline & & Bolivia & 2011 \\
\hline & & Brazil & 2013 \\
\hline & & Chile & 2013 \\
\hline & & Colombia & 2013 \\
\hline & & Venezuela & 2014 \\
\hline
\end{tabular}

seven countries: Argentina, Bolivia, Brazil, Chile, Colombia, Guatemala, and Paraguay (Table 4). The predominant subtype that was identified in 2012-ALJEGX01.0001-that grouped $188(83.5 \%)$ of the isolates, was once again determined to be the predominant subtype in this analysis as well (Campos et al., 2012). Salmonella enterica serovar Enteritidis grouped $70.4 \%$ of the isolates reported from Argentina, Bolivia, Brazil, Chile, Colombia, Guatemala, and Paraguay over a span of 10 years (Table 4).

Escherichia coli O157: $\mathrm{H} 7$ and Shiga toxin producing Escherichia coli non-O157. There are 622 PFGE XbaIPFGE patterns, corresponding to 1185 STEC O157 strains isolated in five countries of the region (Argentina, Chile, Cuba, Paraguay, and Uruguay), in the 1988-2015 period. There is a high clonal diversity, observing the circulation of characteristic subtypes in each of the countries. However, identical subtypes have been found in Argentina and Chile.

According to the information gathered in 2016 (Chinen et al., 2016), data obtained from the surveillance systems for
STEC in Argentina and Chile are presented in Table 5. The other countries showed differences in the frequency of diseases associated with STEC (Table 6).

The most frequent serotypes in the Region are O157:H7 (56.3\%), O145:H- [fliCH28], and O26:H11/H- (13.4\%). In general, cases of Haemolytic uraemic syndrome (HUS) are sporadic, however, outbreaks were reported mainly in a family or in the community.

STEC surveillance represents a challenge in the region due to the severity and sequelae of the diseases it produces, the emergence of new pathotypes and the ability to produce outbreaks. Detection of STEC O157 was associated with two cases of urinary infection in adult women of 72 and 84 years, in Uruguay, in 2010 (Gadea et al., 2012). Detection of 19 hybrid strains EAEC/STEC O59: NM [fliCH19], was associated with cases of HUS and bloody diarrhea, in Argentina, 2005-2015 (Carbonari et al., 2018).

In LA, the notification of diseases associated with STEC and cases of HUS is mainly carried out through syndromic surveillance, through the surveillance of foodborne diseases (Bolivia, Cuba and Paraguay), and/or through the 
Table 3. Salmonella enterica Serovar Typhimurium XbaI Pulsed-Field Gel Electrophoresis Patterns Present in More Than One Country and Frequency of Distribution in Database from 2004 to 2017

\begin{tabular}{lcll}
\hline PFGE-Xbal-pattern & Frequency & Countries & Years \\
\hline ALJPXX01.0027 & $7.34 \%$ & Argentina & $2006-2016$ \\
& & Brazil & 2009 \\
ALJPXX01.0054 & $2.34 \%$ & Paraguay & 2009 \\
& & Argentina & $2008-2013$ \\
ALJPXX01.0068 & $1.21 \%$ & Brazil & 2006 and 2008 \\
ALJPXX01.0094 & $1.13 \%$ & Argentina & 2013 \\
& & Brazil & $2008-2017$ \\
ALJPXX01.0119 & $1.59 \%$ & Argentina & 2010 \\
& & Chile & $2010-2017$ \\
ALJPXX01.0154 & $4.61 \%$ & Argentina & 2016 \\
& & Paraguay & $2010-2016$ \\
ALJPXX01.0165 & $1.74 \%$ & Argentina & 2010,2013 and 2015 \\
& & Brazil & $2009-2016$ \\
ALJPXX01.0230 & & Argentina & 2010 and 2013 \\
ALJPXX01.0267 & $1.44 \%$ & Brazil & $2015-2016$ \\
ALJPXX01.0281 & \multirow{2}{*}{$1.21 \%$} & Paraguay & $2010-2015$ \\
& \multirow{2}{*}{$1.44 \%$} & Argentina & 2015 \\
& & Paraguay & $2011-2016$ \\
& & Argentina & 2016 \\
& & Paraguay & $2010-2016$
\end{tabular}

surveillance system of acute diarrhea (Argentina, Brazil, Chile, Costa Rica, Paraguay, and Peru). The notification of HUS cases is mandatory in Argentina, Bolivia, Brazil, Chile, and Paraguay. Uruguay and Costa Rica do not have a formal surveillance system for HUS and STEC infections. In gen- eral, syndromic surveillance is reinforced with laboratorybased surveillance through its National. The HUS is endemic in some countries of the Southern Cone, being Argentina the country with the highest incidence worldwide, $\sim 10$ cases/ 100,000 children younger than 5 years of age in 2015 .

Table 4. Salmonella enterica Serovar Enteritidis Xbai Pulsed-Field Gel Electrophoresis Patterns Present in More Than One Country and Frequency of Distribution in Database from 2004 to 2017

\begin{tabular}{|c|c|c|c|}
\hline PFGE-XbaI-pattern no. & Frequency & Countries & Year \\
\hline \multirow[t]{7}{*}{ ALJEGX01.0001 } & $70.43 \%$ & Argentina & 2006-2016 \\
\hline & & Bolivia & 2011 and 2013 \\
\hline & & Brazil & $2009-2015$ \\
\hline & & Chile & 2009 and 2011 \\
\hline & & Colombia & 2009 and 2011 \\
\hline & & Guatemala & 2013 \\
\hline & & Paraguay & 2008-2009 and 2013 \\
\hline \multirow[t]{4}{*}{ ALJEGX01.0010 } & $8.32 \%$ & Argentina & $2010,2013,2015$, and 2016 \\
\hline & & Brazil & 2013 \\
\hline & & Guatemala & 2012 \\
\hline & & Paraguay & 2011 and 2013 \\
\hline \multirow[t]{3}{*}{ ALJEGX01.0006 } & $2.59 \%$ & Argentina & 2007 and 2010 \\
\hline & & Brazil & 2013 \\
\hline & & Colombia & 2009 and 2011 \\
\hline \multirow[t]{2}{*}{ ALJEGX01.0009 } & $2.03 \%$ & Argentina & 2007 \\
\hline & & Brazil & 2012,2013 and 2016 \\
\hline \multirow[t]{2}{*}{ ALJEGX01.0026 } & $1.66 \%$ & Argentina & 2016 \\
\hline & & Paraguay & 2011 and 2013 \\
\hline \multirow[t]{3}{*}{ ALJEGX01.0004 } & $1.48 \%$ & Argentina & 2006-2007 and 2013 \\
\hline & & Bolivia & 2009 \\
\hline & & Brazil & 2013 \\
\hline \multirow[t]{2}{*}{ ALJEGX01.0008 } & $0.74 \%$ & Argentina & 2007 \\
\hline & & Brazil & 2013 \\
\hline \multirow[t]{2}{*}{ ALJEGX01.0035 } & $0.55 \%$ & Argentina & 2016 \\
\hline & & Brazil & 2013 \\
\hline \multirow[t]{2}{*}{ ALJEGX01.0015 } & $0.92 \%$ & Argentina & 2006-2007 and 2012 \\
\hline & & Colombia & 2009 \\
\hline
\end{tabular}


Table 5. STEC Infection Cases in Argentina and Chile, with Consolidated Surveillance Systems

\begin{tabular}{lll}
\hline & \multicolumn{1}{c}{ Chile 2007-2013 } & \multicolumn{1}{c}{ Argentina 2011-2015 } \\
\hline Samples received at NRL & 2425 & 2119 \\
Number of STEC strains & $599(24.7 \%)$ & $587(27.7 \%)$ \\
Most frequent serotypes & O157:H7, O26:H11 and O26:H- & O157:H7, O145:HNM and O121:H19 \\
Age group & $67.5 \%$ from 1 to 4 years old & $80.5 \%$ from 1 to 4 years old \\
Gender & $52.2 \%$ male/47.8\% female & $45 \%$ male/55\% female \\
\hline
\end{tabular}

NRL, National Reference Laboratory.

Campylobacter spp. The RDB has 533 Campylobacter spp. isolates corresponding to 249 PFGE patterns (470 C. jejuni strains-206 XbaIPFGE-patterns; 63 C. coli strains43 XbaIPFGE-patterns). They were isolated in Argentina $(n=514)$ and Paraguay $(n=19)$ (Table 7).

The C. jejuni and C. coli strains isolated in Argentina and Paraguay, have shown diversity by SmaI-PFGE. It was interesting to detect the same pattern in both countries suggesting the importance of the investigation in food, as infection source and vehicle of dissemination.

Listeria monocytogenes. The RDB has 208 L. monocytogenes isolates from human and food, corresponding to 66 ApaI-PFGE patterns. They were isolated in Argentina ( $n=514$; human), Costa Rica ( $n=47$; human and food), and Chile ( $n=18$; food and human) (Table 8).

Shigella sonnei. The RDB includes 1283 S. sonnei strains, isolated from Argentina $(n=978)$, Colombia $(n=101)$, Costa Rica $(n=52)$, Paraguay $(n=51)$, Brazil $(n=28)$, Chile $(n=24)$, and Perú $(n=49)$. Out of the total 1273 were analyzed by $X b a \mathrm{I}$ ( 633 different $X b a \mathrm{I}$-PFGE patterns) and 109 by $B \ln \mathrm{I}$ (57 different $B \ln \mathrm{I}$-PFGE patterns).

Vibrio cholerae. There are data from 172 isolates at the $V$. cholerae RDB from 1992 to 2018 from Argentina, Brazil, Chile, Colombia, Ecuador, Paraguay, and Trinidad and Tobago. Out of which, 134 were analyzed by Sfi-PFGE and 74 by NotI-PFGE.

The RDB was useful to study the outbreak $(n=356)$ that occurred in Venezuela (López, 2011) with imported cases

Table 6. Latin America Countries with Low FREQUENCY OF STEC INFECTION CASES

\begin{tabular}{|c|c|c|}
\hline Country & $\begin{array}{c}\text { STEC } \\
\text { associated cases } \\
\text { (diarrhea/HUS) }\end{array}$ & STEC strain isolated \\
\hline Bolivia & 2 HUS & $\mathrm{O} 157$ stx $_{2} ; \mathrm{O} 26$ stx $_{1}$ \\
\hline Brazil & 41 diarrhea & no-O157 \\
\hline Costa Rica & 11 diarrhea & $\begin{array}{l}\mathrm{O} 157 \text { stx } x_{2}(2) ; \mathrm{O} 145 \text { stx } \\
\text { (3); ONT stx } \\
\text { stx } x_{1} \text { eae (2); ONT }\end{array}$ \\
\hline Cuba & 4 diarrhea & no-O157 stx $_{2}$ eae \\
\hline Paraguay & 7 diarrhea & 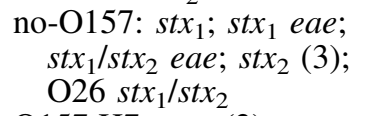 \\
\hline Perú & 4 diarrhea & $\begin{array}{l}\mathrm{O} 157: \mathrm{H} 7: \text { stx } \\
\text { stx } 1 / \text { st } x_{2}\end{array}$ \\
\hline
\end{tabular}

HUS, Haemolytic uraemic syndrome. from República Dominicana on January 22, 2011. By SfiIPFGE the strains showed a $98 \%$ of similarity with one of the Haiti strains, but were different by NotI-PFGE. The outbreak was notified to the focal point of IHR, as a public health event of international concern.

\section{Methodological contributions}

PulseNet laboratories worldwide use PFGE standardized protocols (CDC, Atlanta, GA) for the surveillance of the main pathogens and the participants apply them according to their priorities in each country. In the light of the need in LA to have specific PFGE procedures for Cronobacter sakazakii and S. flexneri, PNLAC had developed and validated their protocols in contribution to improve the laboratory-based surveillance of these pathogens worldwide.

In 2005-2008 in Argentina, C. sakazakii was detected from commercial brands of imported powdered infant formula and not from any human cases until that moment. To have a specific PFGE protocol for subtyping Cronobacter species, an initial development and multicenter validation process (Brengi et al., 2012) was done at INEI-ANLIS, Argentina, working together with four other laboratories: CDC, United States; the National Microbiology Laboratory of Health Canada, Canada; the World Health Organization (WHO) Cronobacter Reference Laboratory, University College Dublin, Ireland; and the Institute for Food Safety and Hygiene, University of Zurich, Switzerland. This protocol was useful to investigate the first episode of fatal cases of neonatal infections associated with Cronobacter malonaticus and $C$. sakazakii in the same hospital in Argentina that occurred from January 2009 through September 2010 (Asato et al., 2013). Also another fatal case associated with $C$. sakazakii occurred in Costa Rica was studied and it demonstrated that the same strain was isolated from the girl and the powdered infant formula that she had sampled at home. The investigation demonstrated that it was related to improper handling of the product.

$S$. flexneri is one of the species more prevalent in LA as well as in less developed regions. Additionally, $S$. flexneri is the most frequently species isolated worldwide; and often related as the cause of outbreaks in settings with poor hygiene or sanitary conditions, and imported cases into developed countries associated with travel. With the objective of promoting the surveillance of S. flexneri, a new protocol (Pichel et al., 2012), highly robust and reproducible, was proposed for subtyping S. flexneri. A multicenter study was conducted in nine PulseNet laboratories located in North and South America, Europe, and Asia [INEI-ANLIS "Dr Carlos G. Malbrán" (INEI-ANLIS) of Argentina (co-coordinating laboratory), U.S. Centers for Disease Control and Prevention 
Table 7. Latin America Countries with CAMPYlobaCter JeJUni Infection Cases

\begin{tabular}{|c|c|c|c|}
\hline PFGE pattern no. & $\begin{array}{c}\text { Frequency in data } \\
\text { among C. jejuni } \\
\text { isolates }(\%)\end{array}$ & Countries (isolates) & Years \\
\hline ALDBRS16.0001 & $2.81 \%$ & Argentina (15) & $2009,2011,2015$ and 2016 \\
\hline ALDBRS16.0005 & $3.00 \%$ & Argentina (15) and Paraguay (1) & $\begin{array}{l}2007,2009,2010,2013,2014, \\
2015 \text { and } 2016\end{array}$ \\
\hline ALDBRS16.0034 & $6.94 \%$ & Argentina (36) and Paraguay (1) & $\begin{array}{l}\text { 2006, 2007, 2008, 2009, 2010, } \\
\quad 2011,2012,2014,2015 \text { and } 2016\end{array}$ \\
\hline ALDBRS16.0051 & $3.00 \%$ & Argentina (14) and Paraguay (2) & $\begin{array}{l}2006,2007,2009,2013,2014 \\
2015 \text { and } 2016\end{array}$ \\
\hline ALDBRS16.0105 & $1.88 \%$ & Argentina (10) & $2009,2011,2013,2014,2015$ and 2016 \\
\hline
\end{tabular}

(CDC; co-coordinating laboratory), Instituto Adolfo Lutz of Brazil, National Microbiology Laboratory of Canada, Instituto de Salud Pública de Chile, Statens Serum Institute of Denmark, Global Disease Detection (GDD) Regional Center at the U.S. Naval Medical Research Unit 3 (NAMRU-3), Egypt, Central Public Health Laboratory of Oman, and Public Health Laboratory Center of Hong Kong, China].

\section{PNLAC moving to WGS}

As one of the aims of PNLAC of improved laboratorybased surveillance according to the international standards, WGS has been established as a new tool in the network, starting as a complement for the existing techniques and according to the national capacities of each network members, giving support to the ones that has no access to the technology, as it started with PFGE.

The implementation of PNLAC started in 2011 in the frame of a regional project of $S$. sonnei to study the diversity in the region and in a global context, and to evaluate the use of WGS for the network for laboratory-based surveillance, including outbreak detection (Baker et al., 2017), with the Wellcome Trust Sanger Institute (WTSI) as partner.

At the beginning, capacity building in genome analysis was the priority, organizing different courses with different analysis approaches, including single nucleotide polymorphisms, and the gene-by-gene based-that is, extended multilocus sequence typing based on WGS.

With sequencing capacity increasing in the region since 2014, the wet laboratory training was incorporated in the courses and the participants of the networks were trained in different workshops and during PNLAC Annual Meetings.
International partners were the key for adopting this new technology in the region for foodborne surveillance, including CDC, Food and Drug Administration, WHO, and WTSI.

In 2016, a working group, including Argentina, Chile, Colombia, and México (Perú was incorporated in 2018) was created to establish future steps for using WGS in PNLAC.

In 2018, most of the PNLAC members (México, Perú, Venezuela, Chile, Argentina, Panamá, Paraguay, Costa Rica, Uruguay, Colombia, and Brazil) had local sequencing capacity (Illumina technology, except Brazil that has Ion Torrent).

The working group agreed in a regional analysis workflow and agreed in the creation of a Regional WGS Database with the principles of the PFGE database in data handling and privacy policies.

In 2018, the working group agreed in a wet laboratory protocol, including optional steps for the variations at the national level, and is working in a regional QC program for WGS and a regional pipeline with regional IT capacity to support the countries. For the countries who need support for the bioinformatics analysis in the first stage of genomic implementation, the working group provides the genomic analysis for specific surveillance questions using the agreed workflow for the network.

\section{Conclusions}

In 2018, PNLAC celebrated its 15th anniversary as a consolidated laboratory-based surveillance Regional Network in foodborne and other enteric pathogens with 24 laboratory members. The network has been installing the capacity, including infrastructure, expert personnel in PFGE,

Table 8. Latin America Countries with Listeria monocytogenes Infection Cases

\begin{tabular}{llll}
\hline & $\begin{array}{c}\text { Frequency in data } \\
\text { among L. monocytogenes } \\
(\%)\end{array}$ & \multicolumn{1}{c}{$\begin{array}{c}\text { Countries/origin } \\
\text { (isolates) }\end{array}$} & \multicolumn{1}{c}{ Years } \\
\hline PFGE pattern no. & $3.8 \%$ & Argentina/human (8) & $1993,1995,1998$ and 2006 \\
ALGX6A12.0001 & $3,8 \%$ & Argentina/human (8) & $1999,2000,2001,2002$ and 2007 \\
ALGX6A12.0005 & $7.2 \%$ & Argentina/human (15) & $2011,2012,2013$ and 2015 \\
ALGX6A12.0006 & $8.6 \%$ & Argentina/human (18) & 2011 and 2013 \\
ALGX6A12.0008 & $1.9 \%$ & Costa Rica/human, food (4) & 2008 and 2013 \\
ALGX6A12.0047 & $2.4 \%$ & Costa Rica/food (5) & - \\
ALGX6A12.0039 & $2.8 \%$ & Costa Rica/food (6) & \\
ALGX6A12.0057 & & &
\end{tabular}


and is moving toward WGS to continue their contribution to enhance the National and Regional Public Health System, in agreement with international standards.

\section{Acknowledgments}

The authors are grateful to all laboratories of PulseNet Latin-American Network.

\section{Disclosure Statement}

No competing financial interests exist.

\section{References}

Asato VC, Vilches VE, Pineda MG, Casanueva E, Cane A, Moroni MP, Brengi SP, Pichel MG. First clinical isolates of Cronobacter spp. (Enterobacter sakazakii) in Argentina: Characterization and subtyping by pulsed-field gel electrophoresis. Rev Argent Microbiol 2013;45:160-164.

Baker KS, Campos J, Pichel M, Della Gaspera A, DuarteMartínez F, Campos-Chacón E, Bolaños-Acuña HM, Guzmán-Verri C, Mather AE, Diaz Velasco S, Zamudio Rojas ML, Forbester JL, Connor TR, Keddy KH, Smith AM, López de Delgado EA, Angiolillo G, Cuaical N, Fernández J, Aguayo C, Morales Aguilar M, Valenzuela C, Morales Medrano AJ, Sirok A, Weiler Gustafson N, Diaz Guevara PL, Montaño LA, Perez E, Thomson NR. Whole genome sequencing of Shigella sonnei through PulseNet Latin America and Caribbean: Advancing global surveillance of foodborne illnesses. Clin Microbiol Infect 2017;23:845-853.

Brengi SP, O’Brien SB, Pichel M, Iversen C, Arduino M, Binsztein N, Jensen B, Pagotto F, Ribot EM, Stephan R, Cernela N, Cooper K, Fanning S. Development and validation of a PulseNet Standardized Protocol for Subtyping Isolates of Cronobacter species. Foodborne Pathogens and Disease 2012;9:861-867.

Campos J, Pichel M, Vaz I, Tavechio AT, Fernandes SA, Muñoz N, Rodriguez C, Realpe ME, Moreno J, Araya P, Fernández J, Fernández J, Campos E, Duarte F, Weiler Gustafson N, Binsztein N, Pérez Gutierrez E. Building PulseNet Latin America and Caribbean Salmonella regional database: First conclusions of genetic subtypes of $S$. Typhi, $S$. Typhimurium and $S$. Enteritidis circulating in six countries of the region. Food Res Int 2012;45:1030-1036.

Carbonari CC, Chinen I, Michelacci v, Campos J, Morabito S, Rivas M. Analysis of draft whole-genome sequences of novel EAEC-STX strains using aries. Proceedings of the 10th International Symposium on Shiga Toxin Producing Escherichia coli. Italy: 2018, p.189.

Chinen I, Zolezzi G, Miliwebsky ES, Schelotto F, Varela G, Hormazabal JC, Fernández J, Weiler Gustafson N, Damiani
E, Montiveros D, Camargo C, Rodríguez D, Bolaños H, Duarte F, Zamudio ML, Águila Sánchez A, Orrego V, dos Santos LF, Dias Gonçalves SV, Lima Festivo M, Ureña S, Soto V, Torres A, Pérez Gutiérrez E, Rivas M. Surveillance and epidemiology of diseases associated with Shiga toxinproducing Escherichia coli in Latin America. XXIII Latin American Congress of Microbiology and XIV Congress. Argentine Microbiology (CAM-ALAM 2016), Rosario, Santa Fe, September 26-30, 2016.

Díaz P, Campos J, Moroni J, Della Gaspera A, Napoli D, Chinen I, Camargo C, Fernandes S, Casas M, Ibelli Vaz T, Rodrigues D, Santos A, Festivo M, Damiani E, Montaño L, León W, Castañeda C, Valenzuela C, Morales A, Morales M, Fernández J, Araya P, Weiler N, Zamudio ML, Lopéz E, Ugarte C, Angiolillo G, Perez E. Genetic diversity of subtypes by PFGE, antimicrobial susceptibility and geographic distribution of endemic isolates of Salmonella Typhi in countries of participants of the Pulsenet Latin America and the Caribbean Network. XXIII Latin American Congress of Microbiology and XIV Argentine Congress of Microbiology (CAM-ALAM 2016), Rosario, Santa Fe, September 26-30, 2016.

Gadea Mdel P, Deza N, Mota MI, Carbonari C, Robatto M, D'Astek B, Balseiro V, Bazet C, Rügnitz E, Livrelli V, Schelotto F, Rivas M, Varela G. Two cases of urinary tract infection caused by Shiga toxin-producing Escherichia coli O157:H7 strains. Rev Argent Microbiol 2012;44:94-96.

López E. National Institute of Hygiene "Rafael Rangel." Ministry of Popular Power for Health. Venezuela. Cases imported from cholera in Venezuela. Report notified to PulseNet LatinAmerica and the Caribbean network. PNALC Annual Meeting. Chile, 2011.

Pichel M, Brengi SP, Cooper KLF, Ribot EM, Al-Busaidy S, Araya P, Fernández J, Ibelli Vaz T, Kam KM, Morcos M, Nielsen EM, Nadon C, Pimentel G, Pérez Gutiérrez E, Gerner Smidt P, Binsztein N, for the Shigella flexneri PulseNet PFGE Protocol Working Group. Standardization and international multicenter validation of a PulseNet pulsed-field gel electrophoresis protocol for subtyping Shigella flexneri isolates. Foodborne Pathog Dis 2012;5:418-424.

Address correspondence to: Enrique Pérez Gutiérrez, PhD

Health Emergency Information and Risk Assessment Health Emergencies Department

Pan American Health Organization/World Health

Organization (PAHO/WHO)

$52523 r d$ Street $N W$

Washington, DC 20037

E-mail: pereze@paho.org 